\title{
Falsafah Alam dalam Konteks Falsafah Ketuhanan Menurut Hamka
}

\author{
The Philosophy of Universe in Hamka's Philosophy of God
}

\author{
ZUL`AZMI YAAKOB ${ }^{1}$
}

\begin{abstract}
Islam via al-Quran strongly stresses the significant existence of nature. The creation of universal nature is considered as ultimate proof of the existence of God, the Creator. Islamic philosophers or religious thinkers tend to relate the significance of nature with living an appreciative life. Hamka on his philosophy of nature relates the creation to philosophy of God without distinguishing sharply between philosophy of nature and philosophy of God, calling his position 'philosophy of life'. He was a prolific Muslim scholar whose influence persists throughout Indonesia, Malaysia, Brunei, Singapore and Southern Thailand. Although Hamka passed away 31 years ago, his philosophy still remained strong in Malay Archipelago because of his greatness. Thus, the aim of this article is to analyze Hamka's philosophy on nature and its relation to philosophy of God as portrayed in his book Filsafat Ketuhanan (Philosophy of God) and Falsafah Hidup (Philosophy of Life).
\end{abstract}

Keywords: philosophy of nature, philosophy of God.

Isu alam sekitar pada hari ini tidak lagi terhad kepada bidang fizikal mahupun teknikal semata-mata. Perbincangannya telah melangkaui sempadan di serata dunia dan mempunyai kaitan dalam pelbagai bidang. Dari perspektif agama, alam adalah ciptaan Tuhan dan merupakan objek yang mengandungi nilai batin atau metafizik tertinggi bagi manusia yang ingin mengenali dan mendekati Tuhan. Sebab itulah alam perlu diamati secara etika dan spiritual bagi masyarakat beragama (Akhtaruddin Ahmad 1997: 7-8). Di kalangan ahli falsafah atau pemikir agama dari dunia Melayu di era moden yang mempunyai pandangan sedemikian, didapati Hamka adalah salah seorang daripadanya. Haji Abdul Malik Karim Amrullah yang dikenali sebagai Hamka (m. 1981M) bukan sahaja cukup terkenal sebagai sarjana Muslim mahupun ulama di negara kelahirannya Indonesia, tetapi juga di dunia Melayu Nusantara seperti Malaysia, Brunei, Singapura dan Thailand (di bahagian selatan). Beliau mempunyai kepakaran yang tidak disangkalkan lagi dalam bidang akidah, falsafah, tasawuf, tafsir, politik, pemikiran Islam dan sastera. Kehidupan beliau dalam era moden begitu banyak memberikan pengaruh kepada masyarakat Melayu di Nusantara sezaman dan selepasnya.

Sehingga ke hari ini, didapati buku, tafsir al-Quran dan kaset Hamka masih lagi digemari dan menjadi pedoman masyarakat Islam Nusantara, tambahan pula beliau juga seorang yang petah berpidato (Abdul Rahman Abdul Aziz 2009: 124 \& 127). Hamka dilahirkan pada 17 Februari 1908 di Kampung Molek yang terletak di Sumatera Barat, Indonesia. Beliau pernah memegang jawatan Ketua Majelis Ulama Indonesia sebelum meninggal dunia pada 24 Julai 1981 (Fatimah Abdullah \& Amira Adnan 2011: 358). Di Malaysia, sumbangan besar beliau dalam bidang pemikiran dan pendidikan Islam dapat

${ }^{1}$ Zul Azmi Yaakob, Ph.D., Senior Lecturer at Department of Theology and Philosophy, Faculty of Islamic Studies, Universiti Kebangsaan Malaysia, 43600 BANGI, Selangor, Malaysia, email: zulazmi@ukm.edu.my 
dibuktikan apabila dianugerahkan Doktor Kehormat oleh Universiti Kebangsaan Malaysia pada tahun 1974. Sebelum itu lagi, beliau telah dianugerahkan Doktor Kehormat oleh Universiti al-Azhar, Mesir pada tahun 1959. Antara jawatan penting yang pernah disandang oleh Hamka semasa hidupnya termasuklah sebagai pensyarah di Universiti Islam Jakarta, rektor Perguruan Tinggi Jakarta dan pegawai tinggi agama Indonesia. Hamka dikatakan telah menghasilkan lebih daripada 50 buah karya utama dalam pelbagai bidang. Di samping itu, beliau juga telah memainkan peranan penting di dalam Pertubuhan Muhammadiyah, iaitu sebuah gerakan Islam di Indonesia, malah pernah terlibat dalam bidang politik serta menganggotai pelbagai parti politik di Indonesia semasa hidupnya.

\section{Kecenderungan Perbahasan Isu Alam Sekitar}

Sarjana alam sekitar Malaysia seperti Zaini Ujang menjelaskan, kebelakangan ini begitu ramai pihak yang prihatin tentang isu krisis alam sekitar. Ada yang mengaitkannya dengan permasalahan sistem pendidikan dan sistem sosial masyarakat, serta terdapat juga pandangan yang mempersoalkannya dari sudut falsafah, teknikal dan sains. Pada hari ini, isu alam sekitar turut menjadi perhatian dalam konteks agama (Zaini Ujang 1993: 3-4). Fenomena sedemikian menggambarkan betapa persoalan alam atau alam sekitar telah menjadi salah satu isu yang semakin penting untuk diperbahaskan, malah adakalanya menjadi isu yang setaraf atau mengatasi bidang lain seperti politik, sukan dan hiburan.

Perbincangan tentang alam dalam ruangan agama bukanlah sesuatu yang baru kerana ajaran ataupun doktrin agama telah memaparkannya sejak awal lagi dari sudut penghayatan zahir dan batin. Cuma, keprihatinan masyarakat masa kini tentang isu alam ataupun alam sekitar terlalu ketara dalam ruangan sains dan teknikal berbanding ruangan agama yang mementingkan pengamatan spiritual. Dalam pemikiran Hamka, beliau secara terang-terangan menjelaskan bahawa kewujudan alam adalah berhubung secara langsung dengan konsep ciptaan dan Pencipta. Dengan kata lain, kewujudan alam sebagai makhluk mempunyai falsafahnya tersendiri yang dikaitkan dengan konsep ketuhanan yang merujuk kepada Allah s.w.t sebagai Pencipta.

Hamka menilai alam sebagai penyebab kepada pembentukan falsafah ketuhanan kerana beliau sebenarnya mengambil iktibar daripada kefahaman al-Quran. Ini diungkapkan sendiri oleh beliau:

Al-Kuran pun sangat menganjurkan mempergunakan akal dan pikiran buat merenung segala keajaiban alam itu. Maka adalah manusia-manusia istimewa, yaitu yang berilmu pengetahuan kerana dapat mengetahui agak sejemput kecil daripada rahsia alam yang tersembunyi itu. . . Dalamkan sedikit lagi renungan atas gerak alam itu. Mengapa Matahari ini tidak pernah terjatuh, mengapa bintang-bintang tidak pernah berkisar? Bola disepakkan anak-anak melanjung tinggi ke udara, akhirnya kembali juga ke bawah. Sebab ringan dia terapung ke atas, sebab berat ia turun ke bawah. Mengapa matahari dan bulan tetap begitu saja, tidak pernah jatuh ke bawah, padahal diapun berat? Sebanyak itu bintang di langit, tak terhitung, tak sekali juga berlaga, tak sekali juga berbentur di antara satu sama lain (Hamka 1979: 3031).

Pengambilan kefahaman di kalangan sarjana Muslim dalam memahami alam daripada keterangan wahyu al-Quran sebagai asas membentuk jiwa yang sentiasa mengingati Tuhan bukanlah sesuatu perkara baru. Jika melihat kepada tokoh falsafah 
Vol. 1: (June) 2012

akhlak Islam sekalipun seperti Ibn Miskawayh (m. 1030M), beliau sendiri sentiasa menjadikan kandungan al-Quran sebagai langkah asas untuk membentuk disiplin ilmu akhlak walaupun turut mengambil kefahaman daripada falsafah etika Aristotle (m. 322 SM). Ini disebabkan Ibn Miskawayh mempunyai keyakinan bahawa agama merupakan sumber utama dalam membangunkan falsafah etika termasuklah ke atas alam (Mohd. Nasir Omar 2003: 24).

Ahli falsafah alam sekitar dari Eropah seperti Robin Attfield menegaskan, kekurangan masyarakat untuk mendalami hubungan alam dengan perintah agama disebabkan mereka sendiri telah meminggirkan agama dalam kehidupan mereka yang sering berpaksikan ketentuan manusia sebagi ukuran baik dan buruk sesuatu perbuatan. Dari segi sejarah falsafahnya, keadaan sekularisasi ini terbit semenjak era Renaisans lagi iaitu di abad ke-17 dan 18 Masihi (Attfield 1998: 147). Walaupun secara zahirnya peranan alam sekitar adalah membabitkan secara langsung dengan kepentingan atau manfaat secara fizikal, namun semua itu jika dikaji secara lebih lanjut, didapati ia amatlah berkait secara tidak langsung dengan manfaat batin iaitu kepada spiritual manusia. Inilah yang perlu ada dalam diri masyarakat beragama.

Sumber alam tidak boleh didominasi dan dieksploitasi demi memenuhi kepentingan nafsu manusia semata-mata, tetapi ia sepatutnya dihargai dan dikagumi (Belsey 1996: 165). Masyarakat perlu prihatin bahawa sumber alam bukan sahaja perlu diambi manfaatnya secara zahir, tetapi secara batin iaitu merasakan kekaguman yang sukar bagi mereka untuk mencipta sedemikian indah rupanya.

Gelombang kesedaran alam sekitar pada hari ini telah menyebabkan munculnya satu pembaharuan ideologi, disiplin ilmu dan cara hidup yang dinamakan sebagai environmentalisme. Ia bukan sahaja meliputi dunia ilmiah, malah mencorakkan bidang budaya, sosial, ekonomi, politik dan sebagainya (Zaini Ujang 1992: 146). Sebagai pengguna sumber alam terbesar, manusia dikatakan bertanggungjawab dalam menawan dan mendominasi alam, malah sebagai agen penggubah paling utama dalam ekosistem (Katiman Rostam \& Asmah Ahmad 2006: 44). Ekosistem bermaksud sistem yang melibatkan interaksi antara satu komuniti (seperti manusia, haiwan dan tumbuhan) dengan alam sekelilingnya yang tidak bernyawa (Noresah Baharom 2007: 380). Biarpun kemunculan ramai aktivis alam sekitar mahupun environmentalis pada hari ini dianggap sebagai satu petanda bahawa nasib alam semakin terbela, akan tetapi ia bukanlah sebagai satu jawapan bahawa mereka semua memiliki falsafah alam yang terikat kemas dengan falsafah ketuhanan untuk dijadikan falsafah hidup masing-masing. Bagi Hamka, walaupun beliau bukanlah seorang aktivis alam sekitar atau environmentalis semasa hidupnya, tetapi beliau tidak pernah memisahkan falsafah alamnya dengan fasafah ketuhanan seterusnya dijadikan sebagai falsafah hidup.

\section{Hubungan antara Alam dengan Tuhan}

Falsafah alam sekitar adalah ilmu yang menumpukan kepada alam dan manusia dituntut agar menggunakan kebijaksanaan mereka semasa bertindak ke atas alam. Alam mestilah dihormati oleh manusia yang merupakan penguna sumber alam terbesar. Falsafah alam sekitar juga merupakan salah satu cabang ilmu falsafah etika. Sebab itu ia juga sering disebut sebagai etika alam sekitar (Beckman 2000: 1). Etika alam sekitar merupakan kajian yang menekankan hubungan, nilai dan status moral manusia terhadap persekitaran mereka termasuklah benda-benda bernyawa dan yang tidak bernyawa. Ia juga merujuk kepada kepentingan alam semula jadi di samping mengambil kira suasana penempatan manusia sebagai pengguna yang terbesar terhadap sumber alam (Brennan \& Lo 2008: 1). 
Dalam Islam, pembicaraan mengenai alam bukanlah bersifat picisan ataupun remeh. Jika merujuk kepada kandungan al-Quran sendiri, didapati isu alam telah dijadikan asas untuk mengenali dan mendekati Tuhan. Dalam masa yang sama, al-Quran juga menjelaskan telah banyak kerosakan alam yang sebenarnya adalah berpunca daripada perbuatan manusia. Ini boleh dilihat dalam surah al-Rum (30:41) yang bermaksud:

Telah timbul berbagai kerosakan dan bala bencana di darat dan di laut dengan sebab apa yang telah dilakukan oleh tangan manusia; kerana Allah hendak merasakan mereka sebahagian dari balasan perbuatan buruk mereka, supaya mereka kembali (insaf dan bertaubat).

Setiap sumber alam yang digunakan perlulah mengambil kira kepentingan dari sudut zahir dan batin. Mungkin sesebuah masyarakat dianggap bertuah kerana memperolehi sumber air minuman yang bersih dengan mudah berbanding sesebuah masyarakat lain yang menghadapi kemarau berpanjangan dan kebuluran. Akan tetapi, sejauh manakah masyarakat yang memilikinya dengan mudah sentiasa berkeupayaan mengaitkan nikmat yang mereka perolehi dengan kesyukuran kepada Penciptanya. Inilah menjadi persoalan. Walau semaju mana sekalipun sesebuah masyarakat, mereka masih lagi bergantung kepada peranan alam termasuklah dalam konteks ibadat. Sebagai contoh, umat Islam masih lagi menggunakan kaedah cerapan anak bulan dalam menentukan tarikh menyambut kedatangan bulan Ramadan dan sambutan hari raya.

Oleh demikian, walau dalam soal penggunaan sumber air sekalipun, ia tidak boleh dipisahkan dari rangkuman agama iaitu merujuk kepada nilai ketuhanan. Islam menuntut umatnya agar sentiasa memastikan sumber air dipelihara dengan baik termasuklah tidak mencemarinya, malah Allah s.w.t mengkehendaki umat Islam sentiasa berada dalam keadaan bersih kerana kebersihan merupakan sebahagian daripada iman. Sumber air yang bersih membolehkan umat Islam menggunakannya dalam taharah dan ibadah. Sebab itulah ajaran Islam ada menjelaskan tentang tujuh jenis sumber air mutlak iaitu air hujan, air laut, air sungai, air telaga, air mata air, air embun dan air salji. Inilah yang menunjukkan alam sentiasa dikaitkan dengan nilai ketuhanan yang disediakan melalui jalan agama (Abul Quasem 1981: 50). Namun kini, keadaan begitu berlainan. Kita dapati begitu banyak sampah dan bahan berminyak yang memenuhi ruangan sungai dan tebing laut, hutan semakin berkurangan, malah air hujan yang turun pada hari ini dikatakan tidak selamat digunakan kerana proses yang dihasilkan adalah melibatkan unsur-unsur bahan tercemar. Keadaan sebegini disebabkan oleh sikap manusia yang tidak memahami alam dari sudut agama secara mendalam bahawa alam adalah milik dan ciptaan Tuhan yang dianugerahkan dalam keadaan baik dan perlu dipulangkan kepada-Nya dalam keadaan yang baik juga.

Menurut Hamka, alam mempunyai nilai falsafah, malah beliau sentiasa menunjukkan betapa pentingnya kewujudan alam sebagai asas logik agar manusia berfikir tentang kewujudan Tuhan. Berdasarkan sejarah falsafah, Hamka sendiri menjelaskan bahawa alam merupakan objek yang mula-mula sekali membawa kepada kemunculan persoalan falsafah. Beliau menulis:

Di Miletos, Asia Minor, tempat perantauan orang Yunani, mulanya timbul falsafah. Di sanalah lahirnya Thales, Anaximandros dan Anaximmenes. Perhatian orang mula-mula sekali ialah kepada alam. Bagaimana terjadinya alam ini, itulah mula persoalan. Hampir 200 tahun lamanya, sejak zaman Thales (625-545 Sebelum Masehi), sampai ke zaman Demokritus (460-260 S.M), edaran perbincangan filsuf-filsuf itu ialah tentang alam dari mana 
Vol. 1: (June) 2012

kejadiannya, apakah terjadi sendirinya atau ada yang menjadikan. . . Nyatalah, setelah diselidiki secara mendalam, sifat-sifat rahsia yang ada pada insan, tidak kurang pentingnya daripada yang ada pada alam. Maka keluarlah sari falsafah: "Insan adalah alam yang kecil, dan alam adalah insan yang besar". Filsuf yang mula-mula membawa soal dari langit ke bumi, atau dari alam ke insan itu ialah Socrates (Hamka 2002: 12-13).

Alam yang disaksikan oleh masyarakat pada hari ini sebenarnya adalah mempunyai tanda-tanda (ayat) kebesaran Allah s.w.t (Ahmad Kamal Abdullah 2010: xi-xiii). Akan tetapi, perasaan manusia terhadap kebesaran-Nya hanya dapat dimanfaatkan bagi mereka yang menggunakaan akal fikiran masing-masing. Manusia dikurniakan akal yang bernilai mengatasi kelebihan yang ada pada haiwan dan tumbuhan apatah lagi makhluk lain seperti tanah dan batu. Namun, akal tersebut menjadi tidak bernilai sekiranya mereka tidak menghargainya dengan baik iaitu tidak menggunakannya untuk berfungsi memahami alam dalam konteks hikmah di sebalik kejadian.

Dalam pemikiran Hamka, alam membantu masyarakat untuk saling terus berpegang dan berkeyakinan bahawa segala yang ada di seluruh alam ini bukanlah secara kebetulan, sebalik secara terancang oleh si Pembuat. Inilah yang membawa kepada maksud lebih mendalam tentang falsafah alam. Falsafah alam membawa manusia mengenali dan mendekati Tuhan sehingga bersepadu menjadi falsafah ketuhanan. Dengan kata lain, falsafah alam atau disebut juga sebagai falsafah alam sekitar adalah peneraju kepada pembentukan dan pemerkasaan falsafah ketuhanan dalam diri manusia. Falsafah ketuhanan bertindak menentukan hala tuju manusia semasa hidupnya. Ia akan menjadi falsafah hidup yang dipegangi oleh mereka. Dalam buku Filsafat Ketuhanan, Hamka ada menyebut:

Tetapi Filsafah Alam itu kemudiannya dikembalikan oleh Socrates kepada Filsafat Diri. Setelah engkau menengadah langit, sekarang sudah masanya engkau meniliki dirimu sendiri. Timbullah permulaan dari Ilmu Jiwa (Psychology) dan Ilmu Akhlak (ilmu Budi Pekerti, Ethika). Murid Socrates Plato yang terkenal menyempurnakan lagi. Lalu timbul hasil penyelidikan tentang adanya Yang Maha Kuasa. Yang Maha Tunggal, Penggerak dari segala. Itulah Tuhan! Dari segi Filsafat, bukan lagi dari segi kedongengan (mythologi). Beliau menyatakan pendapat bahawa di balik alam yang nyata ini, adalah hakikat Yang Maha Tinggi; yang dari sana kita datang, dan ke sana kita akan kembali. Tanda adanya ialah kerana keinginan kita selalu hendak pulang kepadaNya. Dialah kebenaran Yang Mutlak (Hamka 1979: 6).

Penegasan Hamka, agama menyarankan manusia supaya memahami alam dalam bentuk penilaian spiritual agar sampai kepada maksud mengapa alam dijadikan untuk mereka. Semua dijadikan bukan sekadar agar manusia menikmati manfaat fizikalnya secara maksimum semata-mata, tetapi menghargai segala kehidupan di sekeliling mereka. Dengan sebab itulah masyarakat wajib memahami alam dari sudut agama yang sentiasa terikat kemas dengan persoalan spiritual mereka.

Peranan agama adalah membentuk spiritual manusia agar lebih memahami alam dengan penuh mendalam. Ia merupakan satu tuntutan dalam diri mereka yang ingin mengekalkan peranan alam supaya dapat mengenali dan mendekati Tuhan. Oleh itu, masyarakat perlu memastikan kelestarian alam berjaya dilaksanakan bermula dari peringkat metafizik terlebih dahulu iaitu dengan mengikut apa yang dikehendaki oleh agama. Namun begitu, semua ini tidak mampu dilaksanakan dengan jayanya jika 
masyarakat masih beranggapan falsafah alam adalah tidak relevan dikaitkan dengan falsafah ketuhanan. Masyarakat masa kini terlalu terbawa-bawa kepada falsafah materialisme dalam memahami alam sehingga kepada tahap menggandingkan alam tabii dengan aktiviti sains dan teknologi moden yang sebenarnya secara tersirat adalah meminggirkan nilai agama iaitu menjauhkan diri mereka daripada Tuhan (Beringer 2007: 145-146).

Berbalik semula kepada pandangan Hamka, memandangkan beliau merupakan seorang sarjana Muslim, maka sudah tentulah pandangannya banyak merujuk kepada alQuran dan al-Hadith dalam memahami alam sehingga membentuk falsafah ketuhanannya yang tersendiri. Walau bagaimanapun, ini tidak bermakna beliau tidak mempelajari falsafah lain. Hamka sebenarnya turut memahami dan menguasai sedikit sebanyak falsafah alam sekitar dari perspektif falsafah Greek sebagaimana yang pernah diungkapkan beliau sebelum ini.

Antara huraian Hamka yang dikaitkan dengan keupayaan beliau berkongsi pengetahuan tentang falsafah Greek mengenai alam adalah sebagaimana huraiannya mengenai falsafah Aristotle di bawah:

Aristoteles murid Plato mempelopori filsafat berhubung hendak mengetahui Hakikat daripada Yang Ada itu. Dialah 'penggerak' Yang Tidak Bergerak'. Dialah yang Wajib ul Ujud, yang pasti adanya. Adapun Ada yang nampak oleh pancaindera ini hanyalah yang Mumkin al Ujud (Hamka 1979: 6).

Dalam Islam, jika merujuk kepada al-Quran, didapati satu perlapan daripada keseluruhan ayatnya membicarakan tentang alam semula jadi ataupun alam tabii. Peranan penting alam tabii dari segi kehidupan rohaniah dan intelek juga meransang umatnya berusaha menghasilkan pelbagai bidang ilmu yang berkaitan dengannya (Hairudin Harun 2007: 143). Alam tabii mampu meransang manusia yang berkeinginan memahami kaedah ciptaan di sebaliknya dengan penuh mendalam. Ilmu yang dikaji bukanlah hanya ilmu sains dan teknologi sahaja, tetapi termasuklah ilmu yang menjadi panduan kehidupan mereka iaitu ilmu wahyu atau dikenali sebagai ilmu agama.

Alam mempunyai nilai falsafah ketuhanan kerana ia bukanlah dijadikan secara siasia. Meskipun begitu, walaupun alam diperakui memberikan manfaat yang banyak kepada umat manusia, tetapi adakah mereka memahami secara batinnya mengapa alam itu juga wajib dikekalkan kewujudannya? Melihat dari sudut agama, jawapan paling tepat adalah pelestarian alam bertujuan agar manusia sentiasa bersaksikan bahawa semuanya adalah ciptaan dan di bawah pentadbiran Tuhan. Gesaan ayat al-Quran sepertimana dalam surah al-Ghasyiah (88:17-20) merupakan antara tuntutan yang dimaksudkan:

Tidakkah mereka memperhatikan keadaan unta, bagaimana ia diciptakan?

Dan keadaan langit, bagaimana ia ditinggikan binaannya?

Dan keadaan gunung-ganang, bagaimana ia ditegakkan?

Dan keadaan bumi, bagaimana ia dihamparkan?

Hamka menegaskan, alam sekeliling telah mempengaruhi unsur-unsur ketuhanan dalam diri manusia. Walau bagaimanapun, semua itu hanyalah bagi mereka yang menyaksikan alam sekeliling dengan pancaindera masing-masing tetapi dengan satu syarat paling utama iaitu mereka sentiasa menggunakan akal fikiran mereka. Jelas sekali hubungan alam sekitar dengan falsafah ketuhanan menurut Hamka memberikan gambaran bagaimana alam adalah objek teramat penting yang perlu disaksikan oleh pancaindera dan 
Vol. 1: (June) 2012

akal manusia. Alam mempunyai sifat dan kelakuan yang bernilai termasuklah nilai keagungan, keajaiban, malah kegerunan (menakutkan) sehingga memberikan kesan mendalam dalam hati dan fikiran manusia untuk bertindak secara respon seperti pemujaan dan sembahyang. Ini telah disebutkan secara panjang lebar oleh Hamka:

Alam terbentang luas dan manusia hidup di dalamnya. Dengan pancaindera dan akal yang ada padanya, manusia dapat mempersaksikan Alam itu dalam segala sifat dan lakunya. Ada kebesaran, keajaiban dan keindahan, dan ada perubahan-perubahan yang tetap. Kehidupan manusia itu sendiri tidak dapat diceraikan dengan Alam itu. Maka yang mula-mula timbul pada manusia itu adalah perasaan bahawa ada sesuatu yang menguasai Alam ini. Dia yang mengatur dan yang menyusun perjalanannya. Dia yang menjadikan segalanya. Dia Yang Maha Kuasa atas setiap sesuatu yang ada. Kesan Pertama bahwa Ada Yang Maha Kuasa itu meratalah pada segenap manusia. Kerana kesan inilah yang tumbuh bilamana akalnya sudah mulai berjalan. .. Di zaman akal itu mulai bertumbuh (primitif), khayalnya akan Adanya yang Ada itu diberinya berupa, menjadi perlambang daripada perasaannya sendiri. Macam-macamlah perasaan yang timbul di sekeliling kesan tentang Yang Ada itu. Kadang-kadang timbullah takut padanya, dan kadang-kadang timbul pula rasa terharu melihat keindahan dan kebesaran bekas perbuatannya. Maka diadakanlah pemujaan kepada benda-benda yang seram. Kepada batu, pohon kayu seumpama beringin. Gunung atau nyatalah kelihatan bagaimana berkembangnya pemujaan kepada yang gaib itu menurut pengaruh keadaan hidup pada masa itu. Semasa kehidupan gua, disembahlah keseraman rimba dan kayu-kayan dan batu. Kemudian itu disembah gunung. Dan setelah hidup berpindah dari gua batu ke tepi sungai, disembahlah air yang mengalir, dipuja pasang naik dan pasang turun. Dan kadang-kadang disembah juga ikan. Dan di zaman perburuan dipujalah binatang-binatang yang dirasa ada hubungan dengan suku. Apabila kehidupan itu telah maju, dan telah pindah ke zaman bercucuk tanam, mulailah dirasa pertalian yang rapat di antara langit dan bumi, kerana kesuburan tumbuh-tumbuhan bertali dengan hujan dari langit. Maka mulailah mata menengadah ke langit. Di sanalah agaknya terletak rahasia Yang Maha Kuasa itu. . . Dan siang dan malam adalah timbul kerana perjalanan Matahari... maka timbullah prasangka bahwa Matahari pusatnya kekuasaan itu. .. kemudian itu terpikir pulalah bagaimana keindahan bulan purnama dan bagaimana pengaruhnya kepada tanaman-tanaman dan binatang ternak, dan bagaimana pula pengaruhnya kepada pasang naik dan pasang turun. Maka kepercayaan kepada Bulan ... (Hamka 1979: 1-2).

Manusia telah mula berfikir tentang Pencipta yang juga sebagai Pentadbir kerana ia adalah kesan yang wujud dalam perasaan mereka sendiri setelah menyaksikan alam. Oleh itu, pelbagai bentuk perasaan yang timbul dalam perasaan mereka. Ada di kalangan mereka yang berasa takut kepada-Nya setelah melihat kejadian dahsyat (mengerikan) seperti gempa bumi dan banjir, ada juga yang berasa terharu melihat keindahan dan kebesaran yang wujud pada alam seperti ketinggian gunung-ganang menghijau dan keluasan lautan biru. Maka, bukanlah sesuatu yang menghairankan sekiranya semua itu telah mendorong manusia melakukan aktiviti pemujaan atau sembahyang kepada Penciptanya atau kepada bahagian-bahagian alam yang tertentu dan diyakini oleh mereka sebagai mempunyai kuasa 
pusat alam. Semua keadaan ini menunjukkan pemikiran masyarakat terdahulu sudah maju kerana berkeupayaan memikirkan kekuasaan yang ada di sebalik alam yang mereka saksikan. Persoalannya, adakah pemikiran dan perasaan kebanyakan masyarakat pada hari ini juga dikatakan serupa keadaannya dengan masyarakat terdahulu tersebut? Jika ini berlaku, sudah tentu alam sentiasa dihargai dan hormati oleh umat manusia dan tidak berlakunya krisis alam sekitar.

Alam terbentang luas mengelilingi manusia telah diciptakan dalam bentuk penuh keindahan. Peluang sebegini sepatutnya diambil oleh umat manusia dalam mengenali dan mendekati Penciptanya. Dalam konteks falsafah Islam, semua keindahan ini akhirnya kembali kepada konsep ketuhanan bahawa Allah s.w.t adalah Pencipta segalanya. Hamka sendiri ada menyebut tentang kepentingan mencari Tuhan berpandukan kepada keindahan alam. Beliau telah mengambil kefahaman daripada al-Quran dan al-Hadith, malah dijelaskan secara lanjutan:

Maka Sabda Ilahi dan ujaran Nabi itu sentiasa mengandung ajakan agar kita sentiasa merenungkan keadaan si sekeliling kita, keindahan yang meliputi akan segalanya. Jiwa yang suci bersih dapatlah mendengar dan melihat indahnya Alam keliling itu. Di sana terdapat tiga sifat Tuhan: Yaitu Jamal, ertinya Indah. Kedua Jalal ertinya Agung. Ketiga Kamal, ertinya Sempurna. Semua yang ada ini adalah dinding yang membatas kita dengan Dia. Tetapi bilamana kita dengan jiwa yang kuat sudi menembus dinding itu, yakni dengan penglihatan rohani yang bersih, niscaya terbukalah hijab itu. Hanya mata yang lahir ini saja yang melihat batas itu, melihat gunung menjulang, ombak berdebur, awan mengepul di udara, kembang mekar dan indah. Adapun mata rohani mulailah menembus dinding itu. Bukan dinding lagi yang kelihatan, tetapi pencipta dari segalanya itu: 'Allah' (Hamka 1979: 101).

Dalam mana-mana agama sekalipun, para penganutnya perlu memandang alam dalam konteks ia bukannya diwujudkan untuk ditindas. Ini kerana alam adalah milik Tuhan. Masyarakat pada hari ini semakin hari semakin memandang alam sebagai sesuatu yang perlu ditindas. Akibat daripada itu, alam akhirnya telah memberontak dan manusia pula yang ditindas oleh alam. Berbeza sekali dengan masyarakat terdahulu, mereka begitu menghargai alam berbanding masyarakat terkemudiannya (Sindhunata 1993: 117-118). Bencana alam begitu kerap berlaku kebelakangan ini kerana keadaan alam sering tidak distabilkan oleh aktiviti masyarakat, akibat diri masing-masing dikuasai oleh sifat tamak untuk memonopoli dan memanipulasi sumber alam yang sebenarnya bertentangan dengan ajaran Tuhan. Falsafah alam mereka telah terlepas ikatan daripada falsafah ketuhanan.

\section{Alam dalam Membentuk Keyakinan Beragama}

Rahsia alam secara zahir dan batin sudah tidak diminati untuk dikaji oleh umat manusia masa kini memandangkan mereka berasakan kehidupan masing-masing semenjak era Renaisans telah mencapai puncak keseronokan hawa nafsu yang sebenarnya terikat kemas dengan falsafah materialisme. Ia merupakan salah satu penyakit dalaman manusia yang malalaikan sehingga mereka gagal untuk mengamati apa yang tersirat di sebalik alam yang tersurat. Meskipun begitu, bagi mereka yang mempunyai perasaan ingin tahu serta mengaktifkan kekuatan akal masing-masing untuk mengupas segala rahsia alam, maka ungkapan Hamka sebagaimana di bawah perlulah diperhatikan: 
Vol. 1: (June) 2012

Banyak rahsia dalam alam ini. Kita tidak tahu, tetapi ingin tahu. Langit lazuardi yang indah berwarna biru, bintang-bintang cakrawala, dengan matahari dan bulannya, angin yang bertiup sepoi-sepoi basah, nampak semuanya bila kita menegadah ke atas. Kita alihkan pandangan ke bawah, nampaklah dunia, lautan dan daratan, gunung ganang dan padang pasir, hujan turun membasahi bumi, maka hiduplah bumi sesudah matinya; burung-burung terbang dari dahan hinggap ke dahan, demikian juga binatang, margastua yang hidup di dalamnya. Lalu terlihat pula bangsa manusia sendiri, hidup bermasyarakat berpuak-puak, ibu menyusukan anak, ayah mencari makan. Maka terlihat pulalah diri sendiri, dengan keajaiban dan keindahannya. Takjub, hairan, seribu macam atau satu tanda tanya: "Apakah ini? Dari manakah datangnya? Kemanakah kesudahannya?" Rahsia dan penuh rahsia. Bila sedang berfikir hendak menyelidiki, hendak tahu, apakah rahsia itu, kembalilah segala tanya yang sulit tadi kepada yang bertanya: mengapa saya bertanya? Siapa saya? Rahsia. Semua orang ingin memecahkan rahsia-rahsia besar itu. Sebab itulah dapat dipastikan semua orang pada hakikatnya ialah calon filsuf (ahli fikir), meskipun hanya sedikit sekali yang akhirnya jadi filsuf. . . Setelah puas mencari rahsia itu, barulah timbul seorang filsuf luar biasa, yang tidak lagi hendak menagadah ke atas, tetapi mengajak sesama filsuf mengupas satu soal yang lebih besar dari segala soal itu, iaitu: "Kita ini siapa?" (Hamka 2002: 11-12).

Ungkapan Hamka sepertimana di atas juga menunjukkan bagaimana beliau mengaitkan aktiviti mengkaji rahsia alam selalunya merujuk kepada ahli falsafah iaitu golongan yang sering menggunakan akal fikiran dalam mencari persoalan dan mendapatkan jawapan. Ahli falsafah sentiasa cuba memahami alam agar apa yang mereka percayai selama ini bukanlah atas sebab taklid semata-mata atau membuta tuli, tetapi melalui pengamatan dan penyelidikan yang meyakinkan diri masing-masing demi mencapai kebenaran. Justeru itulah ahli falsafah ketuhanan sentiasa menyarankan umat manusia agar memerhati dan berfikir tentang alam dan kehidupannya kerana tujuan murni di sebalik gesaan tersebut adalah untuk menghindarkan umat manusia daripada menjadi golongan yang jumud atau taksub mengikut hawa nafsu dalam mempercayai atau beriman tentang sesuatu perkara termasuklah tentang agama. Walau bagaimanapun, wahyu masih kekal sebagai panduan amat penting dalam memandu manusia untuk berfikir. Ini kerana, gesaan dalam kandungan wahyu turut berperanan memberikan formula atau isyarat kepada manusia untuk berfikir tentang kewujudan dan kekuasaan Tuhan dengan berdasarkan analisis ke atas kewujudan alam.

Bagi Hamka, kecenderungan manusia menjauhkan diri mereka daripada Tuhan adalah disebabkan mereka tidak menggunakan akal mereka dengan baik dalam mengkaji tentang kewujudan alam, sehinggakan matlamat hidup mereka terbawa-bawa dengan kehendak hawa nafsu yang tidak terhenti selagi mana mereka masih bernyawa. Hamka menyebut:

Dan jauh benarlah perbedaan ertinya di antara Percaya (Iman) dengan menurut sajalah. Sebab Iman adalah pendapat sendiri, di dalam perjalanan hidup mencari kebenaran, yakni kesungguh-sungguhan yang tidak pernah berhenti, sehingga insaf kelemahan diri di hadapan Kebesaran Yang Maha Besar. Adapun percaya sajalah! Adalah menurut dengan membuta tuli apa yang dikatakan orang lain, atau apa yang diterima dari guru, sehingga akal 
sendiri menjadi beku tidak bergerak. Dan apabila telah timbul kebekuan itu, beku pulalah paham agama dan tidak lagi bercahaya sinarnya. Itulah yang bernama Taqlid! Taqlid adalah musuh kemerdekaan Akal! (Hamka 1979: 1011).

Penghargaan ke atas sumber alam menjadi tidak bernilai langsung walaupun atas 'tiket' agama, selagi mana manusia telah menjadikan alam yang mengelilingi mereka sebagai sesuatu yang terpisah daripada Tuhan sebagai Pencipta dan Pemilik. Apabila manusia tiada keimanan mengenainya, maka mereka tiada kesungguhan untuk menggunakan akal fikiran, sedangkan agama menggalakkan umat manusia berfikir. Akhirnya, pandangan alam mereka menjadi sekular.

Robin Attfield menegaskan, masyarakat telah memandang alam dalam konteks humanisme sekular yang menjadikan manusia sendiri sebagai paksi penentu kepada masa depan alam sehingga mendominasi dan memanipulasinya. Masyarakat hanya fokus ke arah mendapatkan kebahagiaan, kebebasan dan keadilan bagi diri mereka semata-mata sehingga mengabaikannya dalam konteks mengenali dan mendekati Tuhan, bahkan cuba meminggirkan agama dalam falsafah kehidupan mereka (Attfield 1998: 147). Seorang lagi sarjana alam sekitar dari Barat iaitu Almut Beringer menegaskan, sikap mementingkan diri dan tamak merupakan antara penyakit spiritual yang sering menggagalkan usaha mengaitkan alam dengan Tuhan (Beringer 2007: 148). Masyarakat menjadi terlalu leka dengan tuntutan hawa nafsu sehingga begitu mudah melupakan tuntutan agama (mengaitkan alam sebagai milik Tuhan).

Walaupun dapatan sains dikatakan telah menyebabkan keimanan manusia terhadap Tuhan semakin bertambah, namun situasi sedemikian hanya boleh berlaku bagi mereka yang memiliki ilmu mendalam dan sentiasa bersedia untuk mengenali apakah yang menjadi tonggak kepada pangkal hakikat segala-segalanya, yakni Tuhan adalah Pencipta dan Pentadbir sekalian alam. Situasi tersebut tidak akan berlaku kepada manusia mahupun sarjana yang dikategorikan sebagai materialis dan masih dangkal isi ilmu mereka (Zakaria Awang Soh 1992: 51). Dalam Islam, kedangkalan yang dimaksudkan termasuklah tidak mengambil kefahaman tentang alam daripada sumber wahyu al-Quran dan al-Hadith. Semua ini melibatkan nilai kepercayaan dan keyakinan dalam diri masing-masing. Hamka ada menyebut:

Manusia tidak dipaksa buat percaya. Tetapi kalau akal dan fikirannya berjalan, akal dan fikirannya itulah yang terpaksa percaya juga akhirnya. Orang yang dengan tegas menyatakan tidak hendak percaya, pun terpaksa mencari bentuk kepercayaan lain di luar yang diajarkan agama. Sebab itu dapatlah ditegaskan bahawasanya kepercayaan adalah sebahagian daripada hidup (Hamka 1974: 11).

Berdasarkan kenyataan Hamka di atas, beliau cuba menunjukkan bahawa kepercayaan adalah fitrah dalam diri manusia. Biarpun ada umat manusia yang menafikan sesuatu kepercayaan, namun itu tidak bermakna mereka turut menafikan semua kepercayaan lain. Ini kerana, setiap manusia pasti memiliki sesuatu kepercayaan walaupun bukan dalam bentuk pengakuan yang rasmi.

Falsafah alam juga dikaitkan persamaan maksudnya dengan falsafah tabii. Falsafah tabii adalah konsepsi manusia terhadap alam tabii yang juga disebut sebagai alam semula jadi. Konsepsi sedemikian termasuklah hubungan manusia dengan alam dan peranan alam tabii dalam skema kejadian atau kewujudan. Ia juga merangkumi penjelasan terhadap 
fenomena alam dengan merujuk kepada tabiat atau kuasa tabii. Falsafah tabii meliputi persoalan yang boleh dikaitkan dengan dengan metafizik dan teologi tabii terutama sekali apabila perbahasan tertumpu kepada peranan alam tabii dan hubungan alam tabii dengan Khaliq iaitu Pencipta (Hairudin Harun 2007: 4-5). Masyarakat perlu mengelakkan diri mereka daripada menjadi golongan yang taklid buta iaitu tidak menggunakan akal fikiran mereka sebaik mungkin dalam memperkasakan keyakinan bahawa adanya Tuhan Yang Maha Berkuasa dalam menjadi dan mengatur semua perjalanan alam. Hamka mengungkapkan: "Keperchayaan dan keyakinan itu dipelihara baik2, diasah dan diasuh; dijadikan 'tujuan hidup'... Adakah Yang Maha Kuasa di dalam alam ini selain Allah?" (Hamka 1974a: 11).

Pada hari ini, kebanyakan masyarakat masih beranggapan dan berkeyakinan sepenuhnya bahawa sains moden mampu menyelesaikan masalah alam sekitar. Mereka berpendapat kebanyakan benda dan perkara rumit hanya mampu dicari jalan penyelesaiannya berdasarkan sains moden yang terkenal memberikan kaedah atau jalan penyelesaian yang jelas besertakan bukti (Cunningham \& Cunningham 2006: 374). Walaupun tujuan tersebut dianggap murni, tetapi masyarakat masih lagi tidak berupaya menyelesaikan masalah alam sekitar sepenuhnya selagi mana mereka gagal mengenali lebih mendalam tentang Pemilik alam. Di sinilah agama memainkan peranan sebagai panduan manusia memahami alam untuk mendekati Tuhan. Maka itu, alam menjadi objek bagi mereka untuk mencapai matlamatnya, tetapi mestilah melalui petunjuk yang disediakan oleh agama serta dijanakan melalui kebijaksanaan akal.

Manusia sepatutnya menghargai alam kerana ia adalah anugerah yang menakjubkan dan unik, malah tidak mampu diciptakan oleh manusia sendiri walaupun seekor lalat. Hamka ada menyebut:

Dialah yang berdiri sendiri, mempunyai kekuasaan penuh, mempunyai sifat "Kamal" yang mutlak. Segala perbuatan yang diciptakan-Nya, sempurna tiada tandingan. Tidak ada seorang pun yang sanggup meniru meneladanNya; sedangkan membuat seekor lalat orang tak sanggup, konon meniru menciptakan planet bumi sebuah lagi (Hamka 2002: 199).

Biarpun pada hari ini begitu ramai kewujudan manusia yang cerdik dan pandai, bahkan berupaya menghasilkan produk atau barangan yang dibantu oleh peralatan sains dan teknologi seperti mesin dan jentera, namun keupayaan mereka masih lagi terbatas. Kewujudan selain Allah, walau disembah sekalipun ternyata tidak tidak mampu mencipta benda hidup walaupun sekecil-kecil binatang. Pembicaraan Hamka tentang kelemahan kuasa selain Allah (termasuklah kelemahan kuasa manusia) sepertimana di atas, sebenarnya boleh dikaitkan dengan kefahaman beliau dengan ajaran Islam yang terdapat dalam al-Quran. Ini boleh dilihat dalam surah al-Hajj (22:73) yang bermaksud:

Wahai umat manusia, inilah diberikan satu misal perbandingan maka dengarlah mengenainya dengan bersungguh-sungguh. Sebenarnya mereka yang kamu seru dan sembah, selain dari Allah itu, tidak akan dapat mencipta seekor lalat walaupun mereka berhimpun beramai-ramai untuk membuatnya; dan jika lalat itu merampas sesuatu dari mereka, mereka tidak dapat merebutnya kembali dari lalat itu lemahlah yang menyembah, dan yang disembah. 
Alam yang dianugerahi Tuhan kepada manusia menjadi pendorong bagi mereka yang ingin mendekati-Nya. Namun begitu, alam juga boleh menyebabkan manusia menjauhkan diri mereka dari-Nya. Ia merujuk kepada mereka yang tamak dan lalai dengan keseronokan nikmat dunia. Sebab itulah pentingnya manusia yang beragama tetapi yang sentiasa menggunakan akal fikiran mereka dalam memanfaatkan kewujudan alam secara zahir dan batin.

Menurut ahli falsafah agama seperti Klaus Klostermaier, kepentingan memahami alam sebagai unsur yang mempunyai nilai ketuhanan, bukanlah sebagai jalan terakhir, tetapi sebagai jalan yang sebenar dalam memastikan alam sentiasa dihargai. Dalam agama Hindu mahupun Kristian sekalipun, kedudukan alam adalah wajib dihargai sebagai makhluk ciptaan Tuhan untuk dihormati. Namun kini, kebanyakan sumber alam telah didominasi dan dimanipulasi oleh manusia demi kepentingan diri sendiri. Kegagalan manusia memahami alam dengan baik adalah disebabkan oleh kegagalan mereka memahami ajaran agama (Klostermaier 1993: 7).

Apa yang dapat disimpulkan, falsafah alam menurut Hamka mempunyai ikatan kental dengan falsafah ketuhanan yang mampu menjadi falsafah kehidupan bagi umat manusia. Pada hari ini, isu krisis alam sekitar menjadi antara isu yang semakin tiada kesudahan kerana masyarakat meletakkan kewujudan alam sebagai harta milik mereka, sedangkan semuanya adalah milik Tuhan. Manusia hanya diberikan peluang seketika untuk menjaganya dengan baik sebelum dikembalikan kepada Pemiliknya yang asal iaitu Tuhan. Inilah yang cuba dipaparkan oleh Hamka mengenai sikap manusia pada hari ini yang semakin menjauhkan kedudukan alam daripada nilai ketuhanan. Berlakunya usaha perlucutan pemilikan alam daripada Tuhan kepada manusia, disebabkan oleh kerosakan spiritual mereka yang memiliki pandangan alam yang sekular. Selagi mana umat manusia gagal meyakinkan diri masing-masing bahawa alam adalah milik Tuhan, maka selagi itulah nasib alam sentiasa berada dalam ketidaktentuan, malah menuju kemusnahan kerana masa depannya seakan-akan ditentukan oleh hawa nafsu manusia sebagai paksi membuat keputusan ke atas harta (alam) milik Tuhan. Apabila isu alam sekitar kebelakangan ini menjadi antara topik hangat diperdebatkan sehingga dibawa masuk dalam ruangan agama, maka ia secara tidak langsung seakan membawa satu isyarat jelas bahawa konsep alam boleh dikaitkan dengan konsep ketuhanan. Kegagalan menyelamatkan krisis alam sekitar juga boleh dikaitkan dengan kegagalan manusia mempertahankan konsep ketuhanan dalam falsafah alam. Ia perlu disepadukan semula seterusnya dapat membentuk hala tuju umat manusia yang betul dalam memahami alam dan kehidupan mereka sendiri. Bagi Hamka, alam itu secara zahir dan batinnya mengandungi ketinggian nilai falsafahnya yang tersendiri, tetapi ia begitu terikat kemas dengan falsafah ketuhanan yang akhirnya dibentuk menjadi falsafah kehidupan manusia. Kegagalan manusia mengaitkan falsafah alam dengan falsafah ketuhanan adalah jawapan kepada kegagalan mereka menjaga alam dengan baik.

\section{References}

Abdul Rahman Abdul Aziz. 2009. Nilai mencapai kehidupan sejahtera: pandangan Hamka. MALIM (10): 123-144.

Abul Quasem, Muhammad. 1981. Salvation of the Soul and Islamic Devotions. Bangi: Jabatan Usuluddian Falsafah, Fakulti Pengajian Islam, Universiti Kebangssan Malaysia.

Ahmad Kamal Abdullah. 2010. Simbolisme dalam Puisi Islam di Malaysia. Kuala Lumpur: Dewan Bahasa dan Pustaka.

Akhtaruddin Ahmad. 1997. Islam and the Environmental Crisis. London: Ta-Ha Publishers Ltd. 
Vol. 1: (June) 2012

Attfield, Robin. 1998. Secular humanism and the natural world. Dlm. Robin Attfield \& Katharine Dell. Values, Conflict and the Environment, pp. 147-154. Aldershot: Ashgate Publishing Limited.

Beckman, Tad. 2000. What is environmental philosophy. Dlm. Environmental philosophy, (atas talian) http://www2.hmc.edu/ tbeckman/essays/position.htm. Diakses pada 12 May 2012.

Belsey, Andrew. 1998. Marxism and environmental values. Dlm. Robin Attfield \& Katharine Dell. Values, Conflict and the Environment, pp. 155-167. Aldershot: Ashgate Publishing Limited.

Beringer. Almut. 2007. The "spiritual handshake": toward a metaphysical sustainability metrics. Canadian Journal of Environmental Education (12): 143-159.

Brennan, Andrew \& Lo, Yeuk-Sze. 2008. Environmental ethics. Dlm. Stanford Encyclopedia of Philosophy, (atas talian) http://plato.stanford.edu/entries/ethics-environmental. [12 May 2012].

Cunningham, W.P \& Cunningham M.A. 2006. Principles of Environmental Science: Inquiry and Applications. 3rd ed. Boston: McGraw Hill.

Fatimah Abdullah \& Amira Adnan. 2011. Hamka's concept fo moderation: an analysis. Journal of Islam in Asia June(2): 357-375.

Hairudin Harun. 2007. Dari Sains Yunani kepada Sains Islam. 3rd ed. Kuala Lumpur: Penerbit Universiti Malaya.

Hamka. 1974. Cara Mengenal Tuhan. Kelantan: Pustaka Aman Press.

Hamka. 1974a. Pandangan Hidup Muslim. Kelantan: Pustaka Aman Press.

Hamka. 1979. Filsafat Ketuhanan. Melaka: Penerbitan Abbas Bandong.

Hamka. 2002. Falsafah Hidup. Shah Alam: Pustaka Dini Sdn. Bhd.

Katiman Rostam \& Asmah Ahmad. 2006. Penilaian dan Pengurusan Sumber Alam. Bangi: Penerbit Universiti Kebangsaan Malaysia.

Klostermaier, Klaus. 1993. Ecology and religion: Christian and Hindu paradigms. Journal of Hindu-Christian Studies 6(1): 7-11.

Mohd. Nasir Omar. 2003. Christian \& Muslim Ethics. Kuala Lumpur: Dewan Bahasa dan Pustaka.

Noresah Baharom. 2007. Kamus Dewan. 4th ed. Kuala Lumpur: Dewan Bahasa dan Pustaka.

Sindhunata (trans.). 1993. Dilema Usaha Manusia Rasional: Kritik Sosial oleh Max Horkheimer. Kuala Lumpur: Dewan Bahasa dan Pustaka.

Zaini Ujang. 1992. Environmentalisme dalam Tata Baru Dunia. Kuala Lumpur: Institut Kajian Dasar .

Zaini Ujang. 1993. Pencemaran Alam Sekitar: Perspektif Islam. Kuala Lumpur: Nurin Enterprise.

Zakaria Awang Soh. 1992. Kecanggihan Alam Semesta: Antara Wahyu dengan Pengetahuan Sains. Bangi: Penerbit Universiti Kebangsaan Malaysia. 